\title{
Study on Simulation of Machining Deformation and Experiments for Thin-walled Parts of Titanium Alloy
}

\author{
Yaonan Cheng, Diange Zuo, Mingyang Wu, Xinmin Feng and Yue Zhang \\ The Key Lab of National and Local United Engineering for "High-Efficiency \\ Cutting \& Tools", Harbin Univ. of Sci. and Tech, Harbin, 150080, PR China \\ yaonancheng@163.com
}

\begin{abstract}
Deformation problems are main factors affecting the precision of machining the thinwalled parts. This paper focuses on the thin-walled parts of titanium alloy that is the difficult-to-machine material, based on the analysis of deformation characteristics and force, the milling force mathematical model of the ball-end milling cutter was established. On the basis of the 3D milling model of thin-walled parts of titanium alloy, the deformation regularity and cutting force variations were analyzed with the finite element simulation method. Through the experiments of machining thin-walled parts, the cutting force model was verified. The experiments results and simulations results match well. The work provides an effective basis for further study on the control of machining deformation of thin-wall parts of titanium alloy.
\end{abstract}

Keywords: Thin-walled parts; Titanium alloy; Finite element simulation; Machining distortion

\section{Introduction}

As to further improve of the performance requirements for aviation products, thin-walled parts are widely used in aviation industry [1,2]. The characteristics of such parts include complex structure, high precision, difficult shape coordination, large size of outline dimensions to section, large machining allowance and less stiffness. Most of them are difficult-to-machine materials, such as titanium alloy and high temperature alloy [3]. For the tool, there are serious collapsed blades and wear in milling this material, and the tool durability is low. Under the role of the cutting force, it is easy to produce let-tool and the machining distortion occurs. So it causes the sidewall thick above, following thin, size variance and poor processing [4-6].

As to machining distortion of thin-walled parts, the domestic and foreign scholars have done some research combined with experimental study and the finite element method. Kline had machining error prediction study for the rectangular thin-walled plate under the free boundary condition on side $[7,8]$. Tsai used iterative algorithms for computing cutting forces and surface error [9]. In order to get the maximum machining distortion quickly and efficiently, and facilitate online error compensation, Dr. Wu Kai and Kang Yonggang made some related research $[10,11]$. However, most studies on the finite element simulation of machining and milling force model are for the overall end-milling cutters or ball-end mill cutter [12-14]. It is less research on machining thin-walled parts with single-point carbide tools. In this paper, with the cone ball-end milling cutter for machining centrifugal impeller, the machining process of the thin-walled parts of TC4 titanium was analyzed and milling force prediction model was established. And had simulation of machining deformation for thin-walled parts by the finite element analysis software $[15,16]$. The cutting force and vibration frequency are measured by experiments finally. Comparing simulation results 
with experiments result, the optimal cutting parameters were got and the validity of the cutting force model for machining titanium was verified $[17,18]$.

\section{Force Analysis of Thin-walled Parts Machining}

Figure 1 shows geometric characteristics of ball-end milling cutter cutting. When machining the thin-walled parts, the main factor affecting the size accuracy of the workpiece is machining distortion caused by lack of stiffness, and cutting area is the major factor affecting cutting force. In order to establish the cutting force model, tools need to be micro-differentiation: cutting tool is divided into a number of axial segments, apparently, along the axial direction, each axial segment has $N_{f}$ cutting blades $\left(_{N_{f}}\right.$ is the number of teeth of the tool), and each cutting blade is a piece of a cutting micro-element. At some point, the role of instantaneous cutting tool work together is to participate in cutting microelement. Therefore, through the analysis of the cutting force of the cutting micro-element, we can get the entire tool cutting force model.
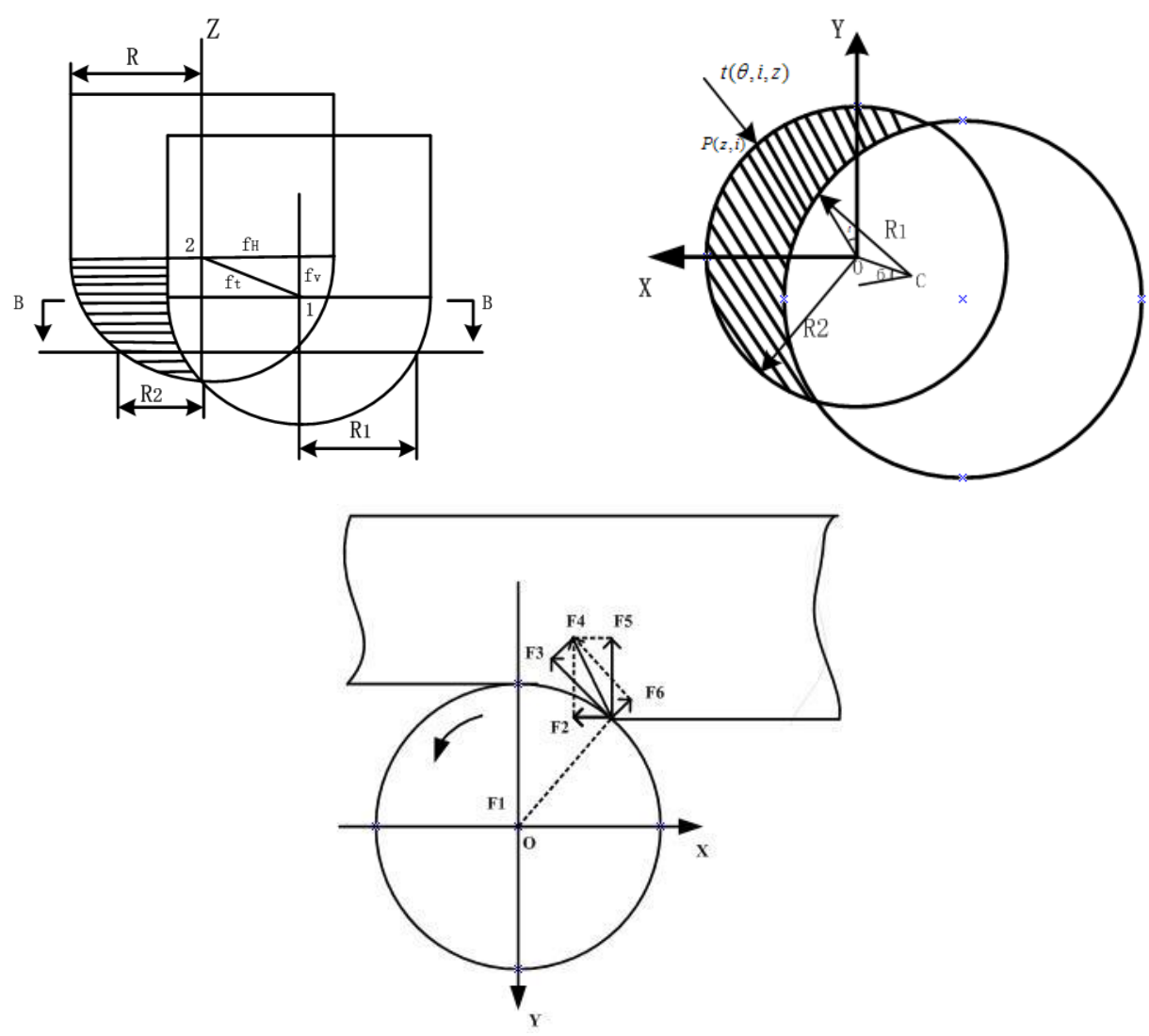

Figure 1. Geometric Characteristics of Ball-end Milling Cutter Cutting

Through the analysis of the cutting micro-element, we can get the corresponding function expression about the geometric cutting radius $\mathrm{R}(\mathrm{z})$, the angular position $(\theta, \mathrm{i}, \mathrm{z})$ and the chip thickness $\mathrm{t}(\theta, \mathrm{i}, \mathrm{z})$.

$\mathrm{z}<\mathrm{R}$, which is the cutting micro-element on the spherical part of the tool:

$$
R(z)=\left(2 R z-z^{2}\right)^{1 / 2}
$$

When cutting micro-element locates on the circumference of the tool:

$$
\beta(\theta, i, z)=\theta-(z / R) \tan \alpha-(i-1)\left(2 \pi / N_{f}\right)
$$

Where, the cutting edge of tool is right-handed, $\alpha$ is the helix angle, $\theta$ is the angle position of the cutter at the tip point. $N_{f}$ is cutter tooth number, $i$ is cutter tooth sequence. 
The radial undeformed chip thickness $t(\theta, i, z)$ of the cutting micro-element $P(z, i)$ on angle position $\beta(\theta, i, z)$ can be expressed as:

$$
t(\theta, i, z)=\left[R(z)-R\left(z+f_{t} \sin \psi\right)\right]+f_{t} \cos \psi \sin \beta(\theta, i, z)
$$

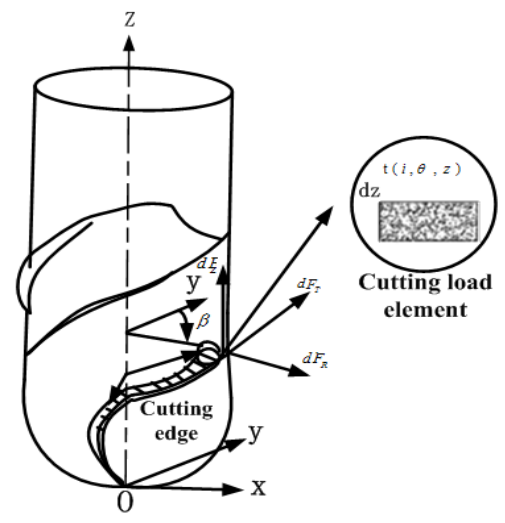

Figure 2. Cutting Micro-element Force of Ball-end Mill Cutter

Figure 2 shows cutting micro-element force of ball-end mill cutter. Through analysis of the geometric characteristics of the ball-end mill cutting:

$d_{F T}(\theta, i, z)$ and $d_{F R}(\theta, i, z)$ are acting forces on $P(z, i)$ in the tangential direction and radial direction, $\mathrm{dz}$ is the cutting width.

Studies have shown that the size of the tangential force and radial force is related with the cutting load, and increases with the cutting load increases, the cutting area is related with the radial undeformed chip thickness and cutting width.

According to tool differential method, at some point, given angle position, the entire tool cutting force could be got by adding up all the micro-element forces involved in cutting.

$$
\begin{aligned}
& F_{X}(\theta)=\int_{d_{1}}^{d_{2}}\left[\sum_{i=1}^{N_{f}} d_{F X}(\theta, i, z)\right] d z \\
& F_{Y}(\theta)=\int_{d_{1}}^{d_{2}}\left[\sum_{i=1}^{N_{f}} d_{F Y}(\theta, i, z)\right] d z \\
& F_{Z}(\theta)=\int_{d_{1}}^{d_{2}}\left[\sum_{i=1}^{N_{f}} d_{F Z}(\theta, i, z)\right] d z
\end{aligned}
$$

Where, $\mathrm{d} 1$ is minimum cutting height, $\mathrm{d} 2$ is the highest cutting height.

The cutting force model based on the cutting layer area is realistic, it can express the instantaneous state of the cutting force and compensate for the lack of empirical model. But the calculation process is more complex, and the experiments design must consider the interaction between the various cutting factors. The coefficient constants to be determined are more. Thus, we use the universal milling force experience model based on the machining materials.

$$
F i=C_{F i} a_{p}{ }^{m F i} a_{w}{ }^{i F i} v^{n F i} f^{t F i} d^{r F i} \quad Z,(i=x, y, z)
$$

Where, $C_{F i}$ is the coefficient determined by the machining materials and conditions. $\mathrm{m}$, $\mathrm{l}, \mathrm{n}, \mathrm{t}$ and $\mathrm{r}$ are the indexes respectively of cutting depth ap, cutting width aw, cutting speed $\mathrm{v}$, feed rate $\mathrm{f}$ and the tool diameter $\mathrm{d} . \mathrm{z}$ is the cutter tooth number. 


\section{Deformation Analysis of Thin-walled Pares with Ball-end Milling Cutter}

The simulation of the finite element method is an important means to predict the deformation regularity of thin-walled parts. In this paper, we establish the 3D milling model for the ball-end mill cutter machining thin-walled parts of titanium alloy with DEFORM-3D finite element analysis software. In the process of finite element analysis, the removed part of the tool material affecting the overall workpiece rigidity must be considered. Using nonlinear finite element method analysis, the workpiece unit is selected body unit, and importing the tool model into the simulation model, we can have intuitive and effective analysis of cutting force variations and the deformation of the workpiece for the single-edged tool. At the same time, we build the tool model taking into account the effect of thin wall thickness. In this article the tapered ball-end milling cutter radius of the ball end is $3 \mathrm{~mm}$. The cutting edge is 2 edges. The rake angle is $8^{\circ}$, the helix angle is $40^{\circ}$. The taper is $3^{\circ}$, the machining hanging deep length is $50 \mathrm{~mm}$. Figure 3 shows the soild model of ball-end mill. Figure 4 shows the finite element simulation model of the tool and workpiece.

The material of the ball end mill is carbide. The workpiece material is the titanium alloys TC4. The size is $80 \mathrm{~mm} \times 45 \mathrm{~mm}$, the thickness is $3 \mathrm{~mm}$. The material constants are $\mathrm{E}=$ $108.5 \mathrm{GPa}, \mu=0.34$. The milling is interrupted cutting and the chip is easily adhered on the cutter tooth. When the adhered cutter tooth cut into the workpiece again, the adhered chip is knocked away and taken away a small piece of tool materials. When milling the thin-walled parts of titanium alloy, using climb milling to have simulation and experiments is good to slow cutter tooth wear. The ball-end mill cutter feeds at a certain speed, the workpiece is fixed in the three directions $\mathrm{X}, \mathrm{Y}, \mathrm{Z}$, and the workpiece surface is local grid refinement. Figure 5 shows the simulation model of the milling process.

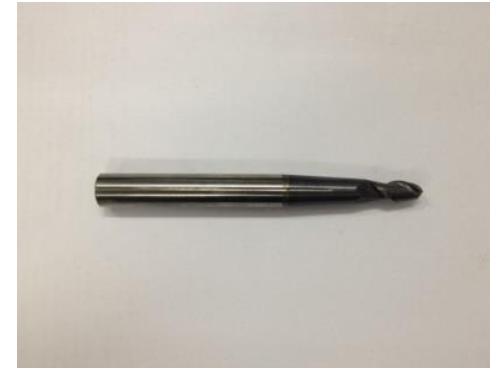

Figure 3. Soild Model of Ball-end Mill Cutter

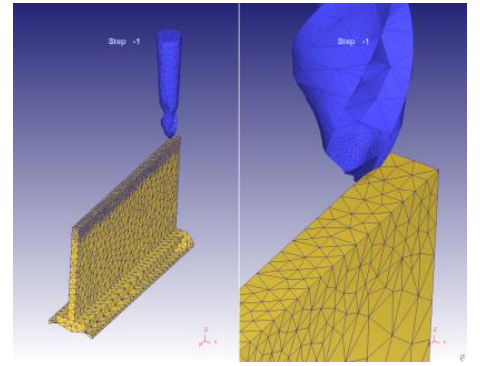

Figure 4. Finite Element Simulation Model of the Tool and Workpiece

From the figure we can observe the machining process of the milling cutter between cutin and cut-out. Figure 5 is the time history of milling by a ball-end milling blade rotated $90^{\circ}$, when rotated $180^{\circ}$ to complete a single blade cutting, another milling blade start to finish the cut-in and cut out process. The entire cyclical process is $0.05 \mathrm{~s}$. Figure 6 shows the cutting force curves of $\mathrm{X}, \mathrm{Y}, \mathrm{Z}$ directions. In the complete cycle process, the milling force of Fx firstly increases, when reaching the crest, that is another milling edge is also involved in the cutting, the milling force begins to decline, until the minimum, and another milling blade begins to cut, that is a cycle of another milling edge starts. According to the comprehensive analysis, as the conduct of the milling, the cutting state becomes stable, the milling force variations also presents regular and smooth fluctuations. The feed force of each cycle shows the variation of increase-reduce-increase, and the overall cutting force variation of Fx is greater than that of Fy and Fz. 


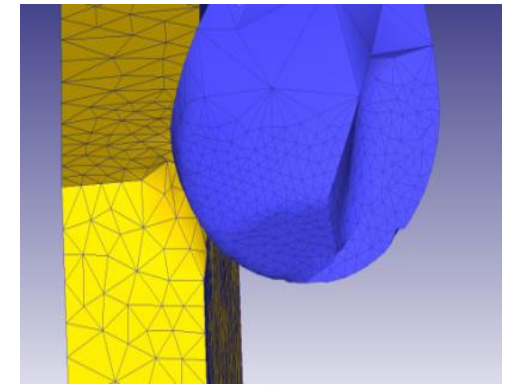

(a) Angle $=0^{\circ}$

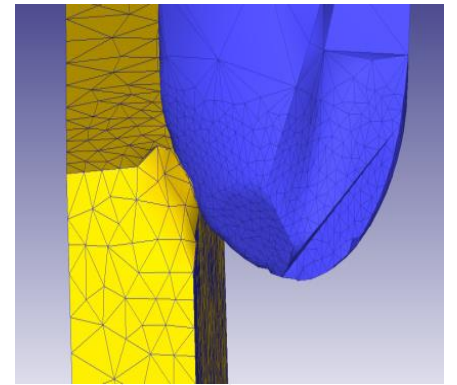

(b) Angle $=45^{\circ}$

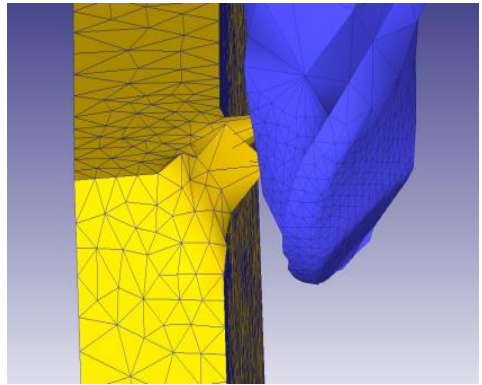

(c) Angle $=90^{\circ}$

Figure 5.Finite Element Simulation of the Different Rotation Angle

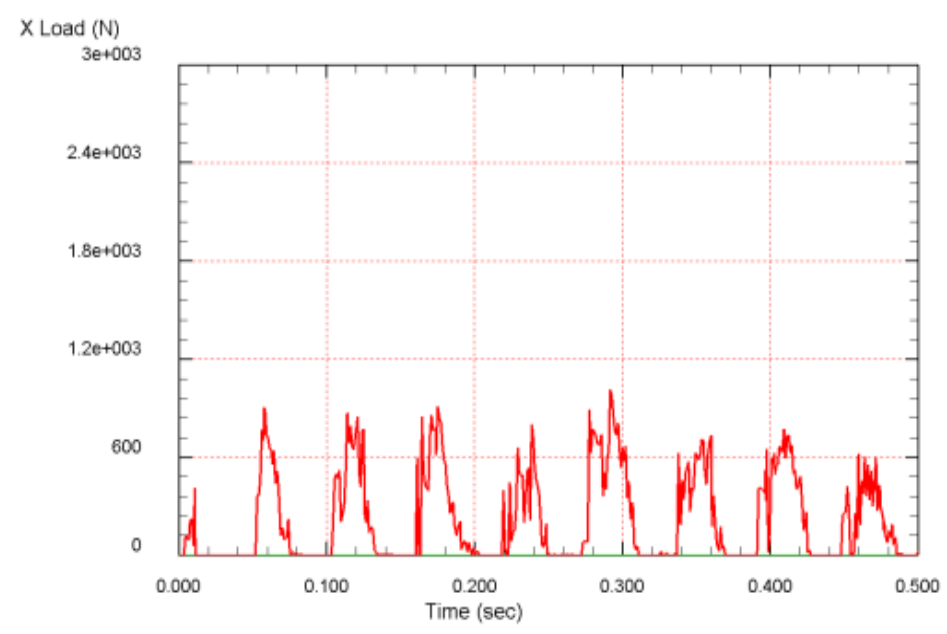

(a) Fx Cutting Force

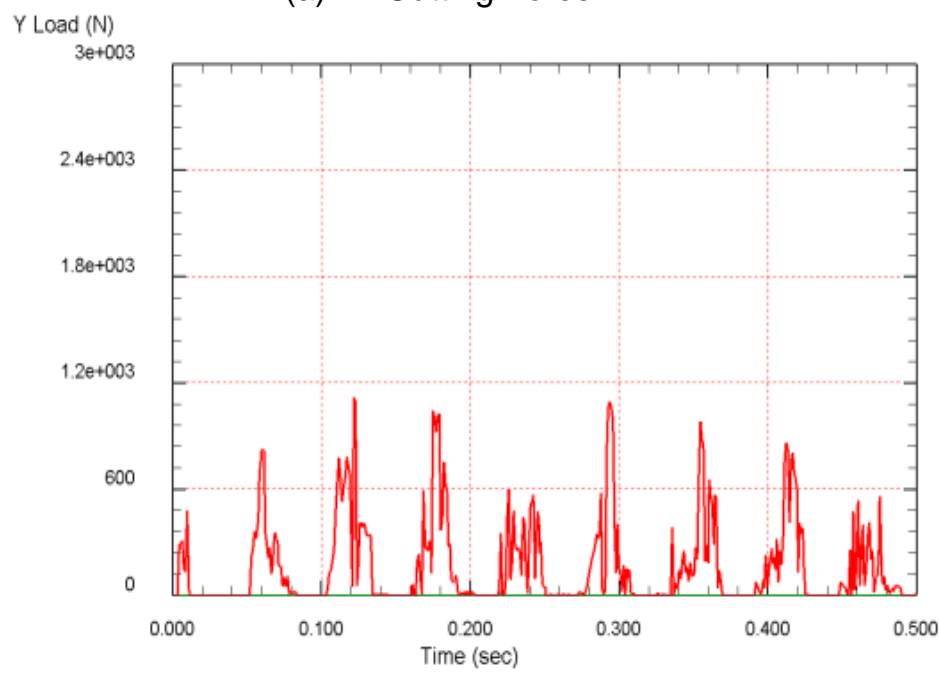

(b) Fy Cutting Forc 


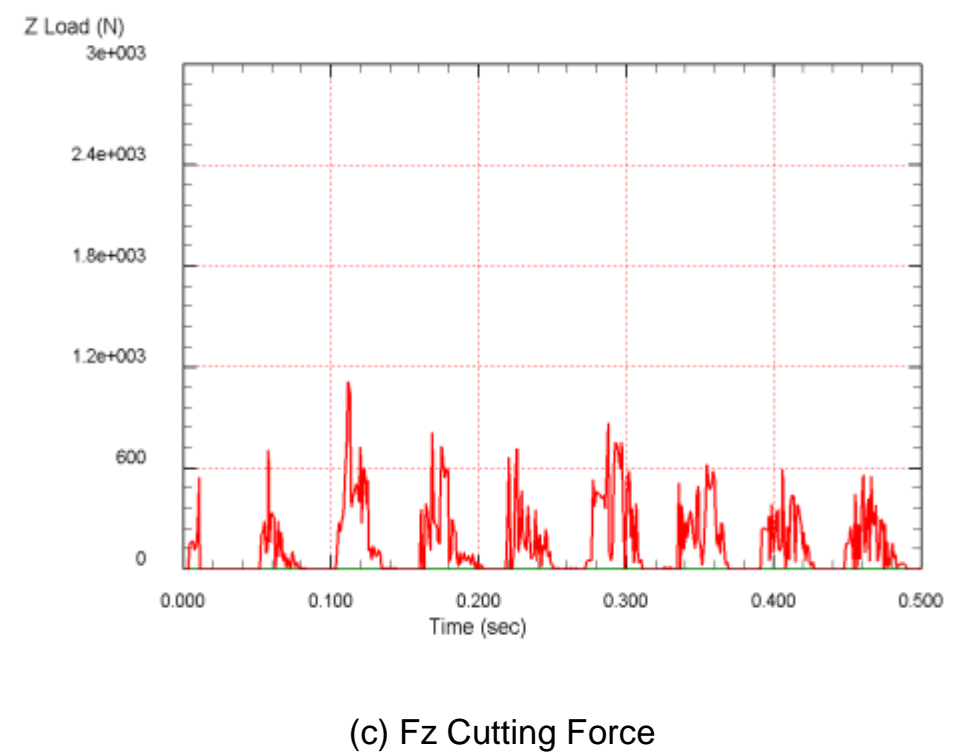

Figure 6. The Results of Cutting Force Simulation

\section{Experimental Verification}

Combined with material characteristics of titanium alloy and the deformation problem of thin-walled parts, the influence of different cutting parameters on cutting forces in three directions is different. Therefore, we have single-factor experiments with the same workpices size by selecting the reasonable cutting parameters. The machine tool is Dalian Machine Tool VDL-1000E, its maximum speed can reach 10000 r/min. The milling force measuring is using a KISTLER dynamometer. Experimental parameters are: spindle speed $\mathrm{n}=3200 \mathrm{r} / \mathrm{mm}$, feed rate $\mathrm{f}=1200 \mathrm{~mm} / \mathrm{min}$, depth of cut ap $=0.5 \mathrm{~mm}$, cutting width aw $=$ $0.3 \mathrm{~mm}$. Tool brande is R216.52-06040RAL12 GC1630. Figure 7 shows processing site of experiment. Figure 8 shows the cutting force curves of the processing site.

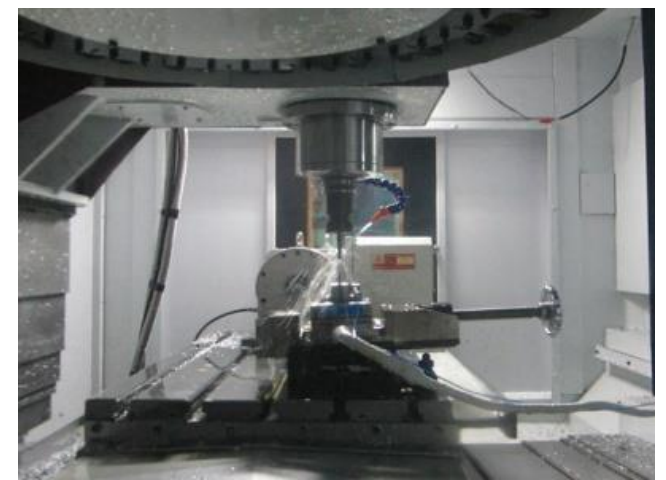

Figure 7.Processing Site of Experiment

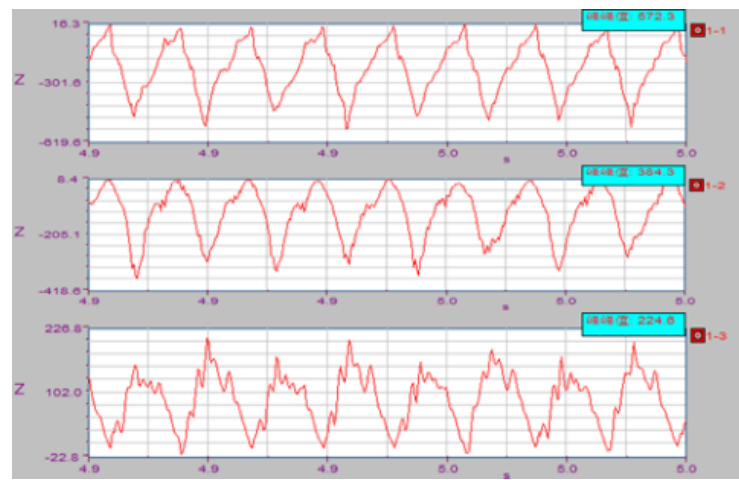

Figure 8. Cutting Force Results

Figure 8 is the cutting force comparison curves between the simulation and experimental results of Fx, Fy, Fz under different feed speed, cutting depth and spindle speed. According to figures show, along with the increase of the speed, the cutting force has corresponding increase, especially in the direction of Fx. Fy and Fz change with the feeding rates are comparable, the cutting force has a large variations with the cutting speed from 500 $\mathrm{mm} / \mathrm{min}$ to $1200 \mathrm{~mm} / \mathrm{min}$. Also, when cutting depth increases, the cutting force will also increase, the increase trend of Fy is significantly, and the simulation results show the same 
positively ratio increase. When the cutting depth is of $0.3 \sim 0.5 \mathrm{~mm}$, the cutting forces in the direction of Fx and Fz have small changes. When spindle speed increase, the cutting force of each direction shows downward trend, and the decline change is greatly, particularly in the direction of Fy. It indicates that when cutting titanium, with the improvement of spindle speed and achieving high speed cutting state, the cutting force decreases in this period, so to provide an effective basis for the selection of cutting parameter. By comparing the three groups of cutting experiments, we can find that the milling force changes small when the milling spindle speed in $3200 \sim 5300 \mathrm{r} / \mathrm{min}$, cutting speed in $800 \sim 1200 \mathrm{~mm}$, cutting depth in $0.3 \sim 0.5 \mathrm{~mm}$, and the tool wear and workpiece deformation decreases, the milling efficiency increases.

Figure 9 shows comparison curves of simulation and experiments. From the experiment results and simulation results we can see that the cutting force of simulation results is less than that of experiment values, the average error is $10 \%$. The changing trend of cutting force components of Fx, Fy matches the experimental results well, but part peak trends of the force differ from the experimental results. This shows that the simulation model does not have a very good expression of pulsation of the cutter and workpiece deformation phenomena, the simulation compiler module also needs improvement.

Based on the analysis of the experiment data, to the force deformation of machining thinwalled parts of titanium alloy with the ball-end cutter, we establish the mathematical model of cutting force. Because the formula of experience model is usually index formula, it is difficult to perform mathematical calculations directly. So we carry on the transformation to deal with it.

Cutting force formula:

$$
F i=C_{F i} a_{p}{ }^{m F i} a_{w}{ }^{i F i} v^{n F i} f^{t F i} d^{r F i} \quad Z,(i=x, y, z)
$$

Transformation:

$$
\ln F_{i}=\ln c_{F i}+m_{F_{i}} \ln a_{p}+l \ln a_{w}+n_{F_{i}} \ln f+t_{F_{i}} \ln v+r_{F_{i}} \ln d
$$

Because the cutting width almost has no effect on single blade cutting, it is not included in the consideration. And d remains unchanged, because the tool we used in the cutting experiments is the same. By processing the coefficients of regression equation, we establish the mathematical model of cutting force of milling titanium alloy.

$$
\begin{aligned}
& F x=56.8 a p^{0.532} v^{-0.867} f^{0.612} \\
& F y=426.8 a p^{0.914} v^{-0.865} f^{0.158} \\
& F z=36.5 a p^{-0.286} v^{-0.156} f^{0.485}
\end{aligned}
$$

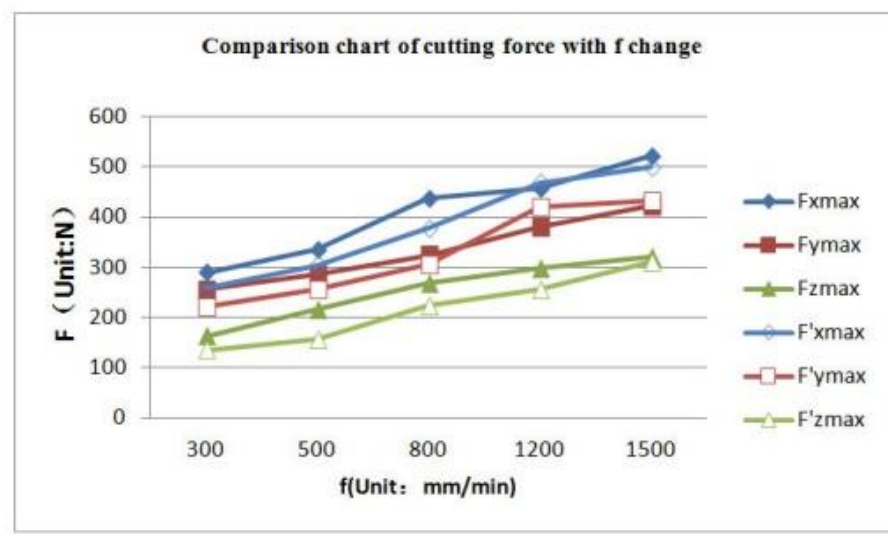

(a) Cutting Force with $f$ Change 


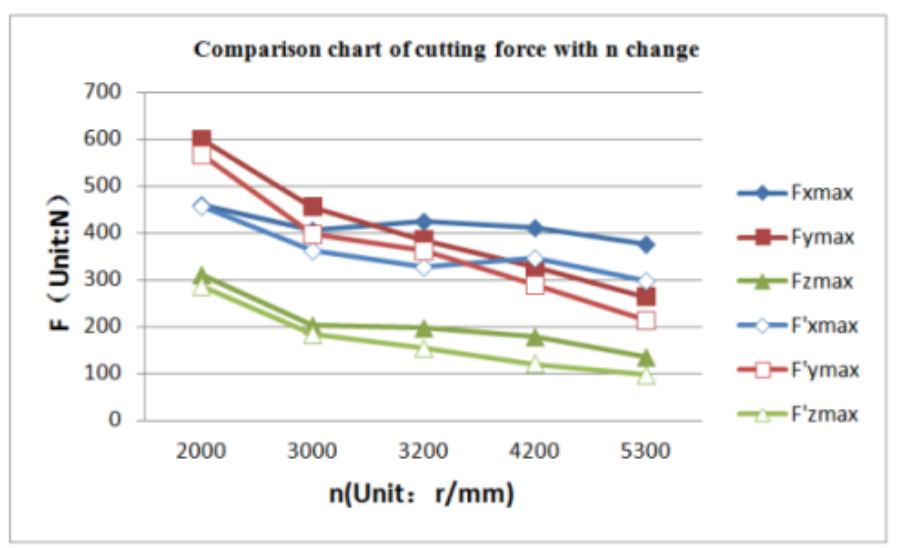

(b) Cutting Force with $\mathrm{n}$ Change

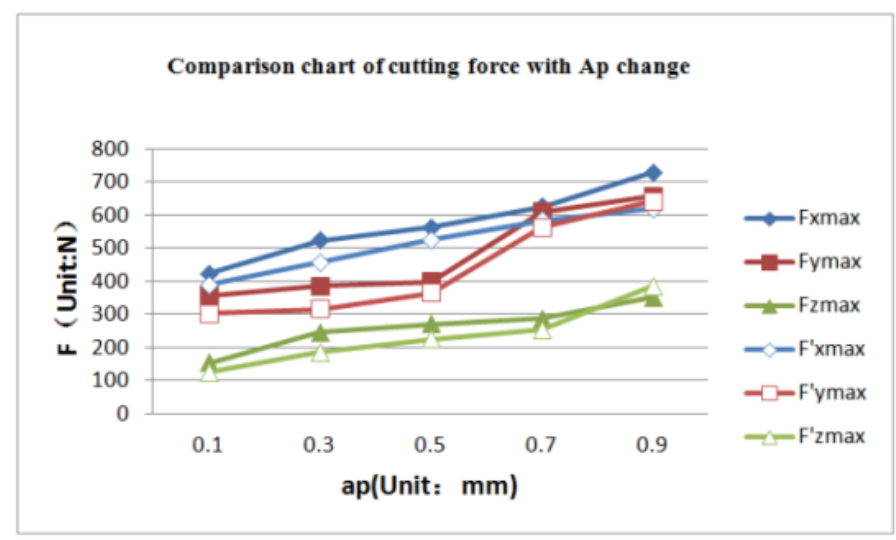

(c) Cutting Force with ap Change

Figure 9. Comparison Charts of Simulation and Experiment

From the above mathematical model of cutting forces, the cutting depth coefficient is relative large, it has greatest influence on cutting force. For cutting speed, the speed the greater the smaller the cutting force, it is consistent with the above experiment results and simulation results. The proof of cutting force model is correct, so to predict the machining deformation regularity caused by cutting force with the model.

\section{Conclusions}

Machining deformation problems are the main factors affecting the accuracy of machining the thin-walled parts. And the cutting force model and deformation prediction is the basis for the control of deformation. For the titanium alloy thin-walled difficult-tomachine materials, on the basis of analyzing its cutting characteristics, and with the method of combining the theoretical modeling, the simulation of software with experimental research, made a detailed study of the cutting force model and deformation forecast, and obtained the following conclusions:

1. Established cutting force mathematical model for machining the thin-walled parts of titanium alloy. Through the stress analysis and modeling for ball-end mill, we got the cutting force model, and verified the validity of the model by the experiment, and lay the foundation for machining deformation forecast for the thin-walled parts of titanium alloy. 
2. The finite element deformation prediction of the thin-walled parts was done. Based on the cutting force model, we built the finite element deformation analysis model of the thinwalled parts. We had the let-tool deformation analysis of the tool and machining deformation measurements with the finite element analysis software. Through the comparison with the simulation data, by using finite element simulation we verify the feasibility of using finite element simulation for predicting deformation of thin-walled parts, so to provide the theory basis for further study on how to control the machining deformation for the small thin- walled parts.

3. We had experimental validation for the cutting force model through machining the thin-walled parts. The results of the measurement show that the calculation precision of the cutting force model is good. And also got that the cutting depth on the effect of cutting force is the largest, and got the range of optimal cutting parameters through the data analysis, so to provide an effective basis for machining deformation forecast.

\section{Acknowledgments}

The research was supported by HarBin Technological Innovation Fund Project for the Talents (2014RFQXJ004).

\section{References}

[1] Z. Q. Ao, J. J. Wu and Z. Q. Wang, "Machine Tool \& Hydraulics", vol. 35, (2007), no. 2.

[2] W. A. Kline, R. E. De Vor and A. Shareef I, "ASME Journal of Engineering for Industry", vol. 104, (1982), pp. 272-278.

[3] J. S. Tsai and C. L. Liao, "Journal of Material Processing Technology", vol. 94, (1999), p. 235-246.

[4] E. Budak, L. T. Tunc, S. Alan and H. Nevzat O zgu ven, "CIRP Annals - Manufacturing Technology61", (2012) pp. 339-342.

[5] H. Guo, D. W. Zuo and S. H. Wang, "Transactions of Nanjing University of Aeronautics \& Astronautics", vol. 22, no. 3, (2005), pp. 234-239.

[6] H. Guo, D. W. Zuo and S. H. Wang, "Key Engineering Materials", (2006), pp. 315-316, pp.174-179.

[7] W. Ma, J. Li and Y. Rong, "The International Journal of Advanced Manufacturing Technology", vol. 15, no. 3, (1999), pp. 171-181.

[8] Mohsen Hamedi, “Artificial Intelligence Review”, vol. 23, no. 3, (2005), pp. 295-311.

[9] K. Kulankara and S. N. Melkote, "International Journal of Machine Tools \& Manufacture", vol. 40, no. 4, (2000), pp. 579-598.

[10] K. Wu, "Study and Control on Machining Deformation for Aviation Thin-wall Compents", NanJing, vol. 64, no. 4, (2002). (in chinese)

[11] Y. G. Kang and Z. Q.Wang, "Journal of Northwestern Polytechnical University", vol. 25, no. 2, (2007), pp. 252-256. (in chinese)

[12] F. Cus and U. Zuperl, "Journal of Materials Processing Technology", vol. 173, no. 3, (2006), pp. 281-290.

[13] H. Z. Li, W. B. Zhang and X. P. Li, "International Journal of Mechanical Sciences", vol. 43, no. 8, (2001), pp. 1711-1730.

[14] J. Gradisek, M. Kalveram and K. Weinert, "International Journal of Machine Tools and Manufacture", vol. 44, no. 4, (2004), pp. 401-414

[15] N. Sebastian, "A Mathmatieal Model for The Estimation of Effects of Residual Stress in Aluminum Parts", Washington University, (2005).

[16] J. E. Wyatt, "Residual Stress in Aluminium Castings", Journal of Materials Processing Technology, vol. 191, no. 1-3, (2007), pp. 170-173.

[17] S. Ratchev, S. Liu and W. Huang, "International Journal of Machine Tools and Manufacture", vol. 46, no. 5, (2006), pp. 542-551.

[18] J. Shyong, T. Chung and L. Liao, “Journal of Materials Processing Technology, vol. 94, no. 2-3, (1999), pp. 235-246. 
International Journal of Control and Automation Vol. 8, No. 1 (2015) 